\title{
FUKUSHIMA: THE DESTRUCTION MECHANISM OF NUCLEAR MATERIALS
}

\author{
L. Bulavin ${ }^{1,2}$, L. Vergun ${ }^{1}$, J. Zabashta ${ }^{1}$, Yu. Plevachuk ${ }^{3}$ \\ ${ }^{1}$ Kyiv National Taras Shevchenko University, Faculty of Physics, \\ 2, Glushkova Ave., Kyiv, UA-03022, Ukraine \\ 2 Institute for safety problems of nuclear power plants of the National Academy of Sciences of Ukraine, \\ 12, Lysohirska St., Kyiv, UA-03680, Ukraine \\ ${ }^{3}$ Ivan Franko National University of Lviv, Faculty of Physics, Department of Metal Physics, \\ 8, Kyrylo and Mefodiy St., Lviv, UA-79005, Ukraine \\ e-mail: plevachuk@mail.lviv.ua \\ (Received April 24, 2017)
}

\begin{abstract}
It was found that the non-fluctuation mechanism of the vacancies formation exists under the influence of neutron irradiation along with the well-known fluctuation mechanism. Unlike the fluctuation mechanism it has a threshold nature, i.e., the vacancies and their clusters begin to form only when the temperature exceeds some critical value $T_{c}$. It was shown that $T_{c}$ is a temperature of the second order phase transition. Compressibility at this temperature tends to infinity, which can lead to destruction of the material.
\end{abstract}

Key words: neutron, swelling, vacancy, phase transition.

PACS number(s): 28.41.Te, 28.52.Nh

\section{INTRODUCTION}

The accident at the Fukushima Nuclear Power Station has raised a number of questions. Some of them remain unsolved to this day. These issues, in particular, include the following. Japan is an earthquake zone. This fact was taken into account when designing the station, so the station construction had the appropriate margin of safety. Fukushima Nuclear Power Station was destroyed by the tsunami. The stresses that occurred in the material as a result of the tsunami did not significantly differ in their magnitude from earthquake stresses. Why the tsunami effect became so devastating? A possible answer to this question is proposed in this article. It is known that the volume of a substance increases under the influence of neutron irradiation. This is called swelling [1-6]Swelling is a result of the processes that can be divided into two stages: the first stage is the formation of vacancies that can merge to form micropores; at the second stage, the process of self-organization causing formation of complex porous structures takes place. The elements of these structures are actually nothing but macrocracks, so the material under load usually breaks at the second phase of swelling. The appearance of vacancies is caused by the temperature increase, which is the result of the substance exposure. It is believed that there is a fluctuation mechanism of their formation, which prevails in the classical theory of vacancies [7]. In this mechanism, the vacancies arise from thermal fluctuations, as reflected by the formula

$$
\tau^{-1}=\tau_{0}^{-1} \exp \left(-\frac{U_{\mathrm{A}}}{k_{\mathrm{B}} T}\right),
$$

where $\tau^{-1}$ is the likelihood of vacancies in this lattice site per unit time, $\tau_{0}$ is a period of thermal vibrations of the atom, $U_{\mathrm{A}}$ is activation energy, $k_{\mathrm{B}}$ is the Boltzmann constant, $T$ is temperature. The concentration of vacancies is defined as the ratio $n / N$, where $n$ is the number of vacancies, $N$ is the number of nodes in a crystal lattice. Denote the concentration of vacancies in the nonequilibrium state through $q$, and in the steady state through $Q$. The classical theory [7], which, as was already mentioned, adopted the fluctuation mechanism, gives the following formula for the equilibrium vacancy concentration

$$
Q=\exp \left(-\frac{W}{k_{\mathrm{B}} T}\right)
$$

where $W$ is the energy of the vacancy formation. The $W$ value is equal to the energy of evaporation, so according to Eq. (2) even near the melting point the concentration of vacancies does not exceed one percent. This is clearly not enough to start the intense swelling. Thus, it is suggested that the non-fluctuation mechanism of the vacancies formation arises under the influence of the neutron irradiation. As is further shown, this mechanism changes substantially the nature of swelling at an early stage and brings a new danger, creating a possibility of the material destruction already at this stage.

\section{THERMODYNAMIC MODEL OF THE VACANCY FORMATION}

We introduce the notation $\Theta=\left(V-V_{0}\right) / V_{0}$, where $V$ and $V_{0}$ are volumes of a system (crystal) in the deformed and undeformed states. We assume that the unstrained state of the system at $T=0$, when external forces are absent.

The non-equilibrium free energy of the crystal with vacancies is written as [7]

$$
f=f(\Theta, T, q) .
$$




\section{BULAVIN, L. VERGUN, J. ZABASHTA, Yu. PLEVACHUK}

The equilibrium concentration of vacancies can be found from the equilibrium condition

$$
f_{q}^{\prime}(\Theta, T, q=Q)=0 .
$$

To get the equilibrium concentration of vacancies the following expression is used

$$
Q=Q(\Theta, T) .
$$

Accordingly, the equilibrium free energy $F$ is expressed as

$$
F=f(\Theta, T, Q(\Theta, T))
$$

To define the compressibility of the crystal with vacancies we write the formula for the equilibrium free energy derivatives:

$$
\begin{gathered}
F_{\Theta}^{\prime}=f_{\Theta}^{\prime}+f_{Q}^{\prime} Q_{\Theta}^{\prime}, \\
F_{\Theta \Theta}^{\prime \prime}=f_{\Theta \Theta}^{\prime}+f_{Q Q}^{\prime \prime}\left(Q_{\Theta}^{\prime}\right)^{2}+f_{Q}^{\prime} Q_{\Theta \Theta}^{\prime \prime} .
\end{gathered}
$$

Condition (4) in other values has the form $f_{Q}^{\prime}=0$, so, Eq. (8) can be simplified

$$
F_{\Theta \Theta}^{\prime \prime}=f_{\Theta \Theta}^{\prime}+f_{Q Q}^{\prime \prime}\left(Q_{\Theta}^{\prime}\right)^{2} .
$$

By definition of compressibility we have

$$
\chi=-V^{-1} V_{p}
$$

where $p$ is pressure.

Taking into account the obvious expressions

$$
\begin{gathered}
F_{\Theta \Theta}^{\prime \prime}=V_{0}^{2} F_{V V}, \\
F_{V V}=-p_{V}, \\
V_{p}=p_{V}^{-1},
\end{gathered}
$$

we can get an equation for compressibility:

$$
\chi=\frac{V^{-1} V_{0}^{2}}{F_{\Theta \Theta}^{\prime \prime}} .
$$

\section{MICROSCOPIC MODEL OF THERMAL VACANCY FORMATION: NON-FLUCTUATION MECHANISM}

It was shown in our paper [8] that in addition to the fluctuation mechanism of the vacancy formation, which is the basis for the classical theory, another one, namely, non-fluctuation mechanism of vacancy formation is possible. To prove this, the case was considered at $\mathrm{T}=0$, when thermal fluctuations were excluded from consideration. Instead, the system was subjected to external tensile strength. Do any vacancies occur in this case? We selected a simple calculation model, i.e., a crystal with a simple cubic lattice with a power potential $u$ of the interparticle interaction

$$
u=\varepsilon\left(-\frac{m}{m-g}\left(\frac{a}{a_{0}}\right)^{-g}+\frac{g}{m-g}\left(\frac{a}{a_{0}}\right)^{-m}\right),
$$

where $\varepsilon$ is the bond energy, and 0 are translational lattice periods in the deformed and undeformed states.

We considered the case of single vacancies, that is, the probability of finding vacancies in the neighboring nodes was neglected. The energy model in the Izing approximation was found to be

$$
U=\frac{1}{2} N u z(1-q),
$$

where $z$ is the number of nearest neighbors.

After determination of the lattice period, formula (16) was rewritten as

$$
\begin{aligned}
U= & N \frac{\varepsilon z}{2}\left[\frac{g}{m-g}\left(\frac{1+q}{1+\Theta}\right)^{m / 3}\right. \\
& \left.-\frac{m}{m-g}\left(\frac{1+q}{1+\Theta}\right)^{g / 3}\right](1-q) .
\end{aligned}
$$

As a result of minimizing the expression (17) for the equilibrium concentration of vacancies, a formula has been obtained

$$
Q=\left\{\begin{array}{r}
0, \quad\left(\Theta<\Theta_{c}\right) \\
\beta\left(\Theta-\Theta_{c}\right), \quad\left(\Theta>\Theta_{c}\right),
\end{array}\right.
$$

where the coefficients $\beta$ and $\Theta_{c}$ are expressed as

$$
\begin{gathered}
\beta=\left[\frac{m\left(\frac{g}{3}-1\right)}{g\left(\frac{m}{3}-1\right)}\right]^{\frac{3}{m-g}}, \\
\Theta_{c}=\beta^{-1}-1 .
\end{gathered}
$$

Our calculation revealed that vacancies can occur under the influence of mechanical deformation only, without any heat energy. Therefore, this new mechanism was named "non-fluctuation".

In this case, vacancies appear due to the fact that the perfect crystal loses mechanical stability under strain $\Theta_{c}$ and the crystal with vacancies appears more stable. In other words, the non-fluctuation mechanism has a threshold: the vacancies appear when the deformation exceeds some critical value $\Theta_{c}$.

In fact, in this case we are dealing with a phenomenon that in mechanics is called a loss of stability at appearance of related forms of equilibrium, see [9]. In this sense, the behavior of the crystal is similar to the behavior of the Euler rod under a compressive force [9]. The formation of vacancies under mechanical deformation is caused by the fact that vacancies affect the energy value in two 
ways. Breaking the bonds, which accompanies the formation of vacancies, leads to an increase in energy. On the other hand, the emergence of vacancies reduces the connection stretching around, which reduces the system energy. The competition between these factors explains the threshold nature of the mechanism: vacancies arise when the second factor starts to dominate.

A possibility of the non-fluctuation mechanism appearance in the absence of external forces at $T>0$ has been discussed in our work [10].

As mentioned above, this mechanism occurs when the system is exposed to tension. In the previous case $(T=0)$ the tension was created by external mechanical forces. When $T>0$, there is another opportunity to create a deformation, namely, by thermal expansion. So, the non-fluctuation mechanism, in principle, can emerge at $T>0$, and it can arise without external mechanical forces, but solely through thermal expansion. Let us express the relationship between the deformation $\Theta$ (now it is the volumetric thermal expansion) and the temperature as a function

$$
\Theta=\varphi(T)
$$

The critical value of deformation $\Theta_{c}$ is achieved at $T_{c}$, which is determined from the ratio

$$
\Theta_{c}=\varphi\left(T_{c}\right) .
$$

Numerical calculations gave a value $\Theta_{c} \approx 0.09$ [8]. An analysis of the reference data showed that this value cannot be achieve by thermal expansion at temperatures lower than the melting temperature.

As was already mentioned, the formation of vacancies through the non-fluctuating mechanism is accompanied by two competing factors: decoupling and relaxation of tensile stresses in the vicinity of the vacancy. The meaning of $q$ is actually a relative portion of empty units in a lattice.

While $q$ has the same value, most bonds break, if we are dealing with single vacancies [8]. The number of broken bonds at a given value of $q$ can be significantly reduced if we assume a possibility of a vacancy cluster formation, - i.e., pores of different shape, which in turn should lead to a decrease in the critical deformation $\Theta_{c}$.

This idea was realized in [10]. Assuming the possibility of the formation of pores immediately after reaching the critical deformation, the energy is

$$
U=\frac{1}{2} N u z(1-\xi q),
$$

where $\xi \sim 0.1$ is a constant, which takes into account the vacancy association in clusters.

Substituting (17) in (23) and minimizing the resulting expression, we get

$$
Q=\left\{\begin{array}{r}
0, \quad\left(T<T_{c}\right) \\
\beta_{1}\left(\Theta-\Theta_{c}\right), \quad\left(T>T_{c}\right)
\end{array}\right.
$$

in which the coefficients $\beta_{1} \Theta_{c}$ are determined as

$$
\beta_{1}=\left[\frac{m\left(\frac{g}{3}-\xi\right)}{g\left(\frac{m}{3}-\xi\right)}\right]^{\frac{3}{m-g}},
$$

$$
\Theta_{c}=\beta_{1}^{-1}-1
$$

Numerical evaluation according to formulas (25), (26) gave the acceptable values $\Theta_{c} \approx 0.04$.

\section{THE FORMATION OF VACANCIES BY THE NON-FLUCTUATING MECHANISM: A PHASE TRANSITION OF THE SECOND ORDER}

Substituting expression (24) in (9), we get

$$
F_{\Theta \Theta}^{\prime \prime}=\left\{\begin{aligned}
f_{\Theta \Theta}^{\prime \prime}, & \left(T<T_{c}\right) \\
f_{\Theta \Theta}^{\prime \prime}+f_{Q Q}^{\prime \prime} \beta_{1}^{2}, & \left(T>T_{c}\right) .
\end{aligned}\right.
$$

Substituting (27) in (14), we conclude that at $T=T_{c}$ the compressibility reveals a drastic jump

$$
\Delta \chi=V^{-1} V_{0}^{2}\left(\frac{1}{f_{\Theta \Theta}^{\prime \prime}}-\frac{1}{f_{\Theta \Theta}^{\prime \prime}+f_{Q Q}^{\prime \prime} \beta_{1}^{2}}\right) .
$$

The compressibility jump means that $T_{c}$ is the temperature of the second order phase transition [11]. It is also known [12] that the compressibility jump at the point of the second order phase transition is the result of the mean field approximation when the system is characterized by a single value of the order parameter $\varphi$, i.e., the spatial field $\varphi(x)$ is considered to be uniform.

In our model $\varphi=1-q$ is the order parameter. Indeed, at $T<T_{c}$ we are dealing with an ideal crystal, and translational symmetry is typical for the system. Accordingly, the order parameter is $\varphi=1$. The appearance of vacancies results in the disappearance of the transmitting symmetry, and a change of symmetry occurs at the phase transition point $\left(T=T_{c}\right)$. The value $\varphi=1-q$ of the order parameter is attribute to the whole system. In other words, we "work" in the mean-field approximation. So, no surprise that we got the jump of compressibility at $T=T_{c}$.

In fact, the $\varphi(x)$ field is inhomogeneous. Thus, it is concluded [12] that in the vicinity of the phase transition point the compressibility is defined by the formula

$$
\chi= \begin{cases}\left(T_{c}-T\right)^{-\gamma^{\prime}}, & \left(T<T_{c}\right) \\ \left(T-T_{c}\right)^{-\gamma}, & \left(T>T_{c}\right),\end{cases}
$$

where $\gamma^{\prime}, \gamma$ are critical indices.

According to (29), relation

$$
\chi \rightarrow \infty, \quad\left(T \rightarrow T_{c}\right)
$$

is valid. 


\title{
L. BULAVIN, L. VERGUN, J. ZABASHTA, Yu. PLEVACHUK
}

Generally compressibility determines a system response to the load. Relation (30) refers to the static compressibility. The term "static" means that the frequency of the load $\omega$ is zero. It is clear that the zero frequency is an idealization, actually we are always dealing with the dynamic compressibility $\chi^{\prime}$. So, we can write

$$
\chi^{\prime} \rightarrow \chi, \quad \omega \rightarrow 0 .
$$

Combining (30) and (31) in one expression we receive

$$
\chi^{\prime} \rightarrow \infty, \quad\left(T \rightarrow T_{c}, \omega \rightarrow 0\right) .
$$

Equation (32) means that at low load values the dynamic compressibility becomes higher in the vicinity of $T_{c}$. These values are also higher in case when the frequency of the load is lower and the temperature is closer to $T_{c}$. In such circumstances, even relatively small loads can cause a significant deformation and destruction of the material.

\section{CONCLUSIONS}

It was found that the non-fluctuation mechanism of thermal vacancies formation under the influence of neu- tron irradiation exists along with the well-known fluctuation mechanism. Unlike the fluctuation mechanism, the latter has a threshold value, i.e., the vacancies form only when the temperature exceeds some critical value, which can be significantly lower than the melting temperature. This fact indicates that the vacancy formation is a phase transition of the second order. Consequently, compressibility becomes high in the vicinity of the critical temperature, tending to infinity if the frequency of the load goes to zero. This means that even small loads destroy the material at this temperature. It is essential that these loads must be of low frequency. It is possible that the earthquake and the tsunami provoke the same maximum tension in the material with a temperature close to the critical temperature. But the frequency of the load in the second case is much smaller, and as the events occur in the vicinity of the phase transition temperature, the compressibility in this case is much greater and therefore the probability of destruction is higher. Thus, the destruction of nuclear materials at the Fukushima station was caused by the fact that during the tsunami the temperature of these materials was close or equal to the temperature of the second order phase transition, corresponding to the formation of vacancies by the nonfluctuation mechanism.
[1] L. K. Mansuz, Mechanisms $\alpha$-kinetics of Radiation Effects in Metals and Alloys. Kinetics of Nonhomogeneous Processes, edited by G. R. Freeman (Wiley \& Sons, New York, 1987), p. 377.

[2] B. Margolin et al., J. Nucl. Mater. 480, 15 (2016).

[3] A. S. Kalchenko, V. V. Bryk, N. P. Lazarev, V. N. Voyevodin, F. A. Garner, J. Nucl. Mater. 437, 415 (2013).

[4] W.'M. Ye, X. L. Lai, Y. Liu, Y. G. Chen, Y. J. Cui, Nucl. Eng. Des. 265, 262 (2013).

[5] B. M. Ma, Nucl. Eng. Des. 28, 1 (1974).

[6] E. Getto et al., J. Nucl. Mater. 477, 273 (2016).
[7] J. Frenkel, Kinetic Theory of Liquids (Peter Smith Publisher, Gloucester, 1984).

[8] L. A. Bulavin O. Yu. Aktan, Yu. F. Zabashta, Phys. Solid State 50, 2270 (2008).

[9] J. Panovko, I. Gubanova, Stability and Oscillations of Elastic Systems (Nauka, Moscow, 1987).

[10] L. A. Bulavin, O. Yu. Aktan, Yu. F. Zabashta, Phys. Solid State 52, 712 (2010).

[11] L. D. Landau, E. M. Lifshitz, Statistical Physics (Nauka, Moscow, 1982).

[12] Z. Patashinskii, V. L. Pokrovskii, Fluctuation Theory of Phase Transitions (Pergamon Press, Oxford, 1979).

\section{ФУКУСІМА: МЕХАНІЗМ РУЙНУВАННЯ ЯДЕРНИХ МАТЕРІАЛІВ}

\author{
Л. Булавін ${ }^{1,2}$, Л. Вергун ${ }^{1}$, Ю. Забашта ${ }^{1}$, Ю. Плевачук ${ }^{3}$ \\ ${ }^{1}$ Київсъкий націоналъний університет імені Тараса Шевченка, \\ фізичний факультет, кафедра молекулярної фізики, просп. Глушкова, 6, Київ, 03022, Украӥна \\ 2 Інститут проблем безпеки атомних електростанцій, вул. Лисогірсъка 2, Київ, 03680, Украӥна \\ 3 Львівсъкий національний університет імені Івана Франка, \\ фізичний факультет, кафедра фізики металів, вул. Кирила і Мефодія, 8, Львів, 79005, Україна
}

Установлено, що під дією нейтронного опромінення, поряд із відомим - флуктуаційним, функціонує ще один - нефлуктуаційний механізм утворення вакансій. На відміну від флуктуаційного, він має пороговий характер: у цьому випадку вакансії та їхні кластери починають утворюватися лише тоді, коли температура перевищить деяке критичне значення $T_{c}$. Показано, що $T_{c} \in$ температурою фазового переходу другого роду. Завдяки цьому стисливість за цієї температури прямує до нескінченності, що може призвести до руйнування матеріалу. 